\title{
Adam Creuziger Shares New Insights into Cruciform Sample Design
}

\author{
Lynne Robinson
}

\section{young professional technical notes}

Young Professional Technical Notes is an occasional feature highlighting the scientific interests and professional accomplishments of an early career TMS member who has contributed to the technical content of the current issue of JOM. The development of this feature is a special project of the TMS Young Professionals Committee. For additional information, contact Lynne Robinson, Magazine Editor, JOM, at Irobinson@tms.org.

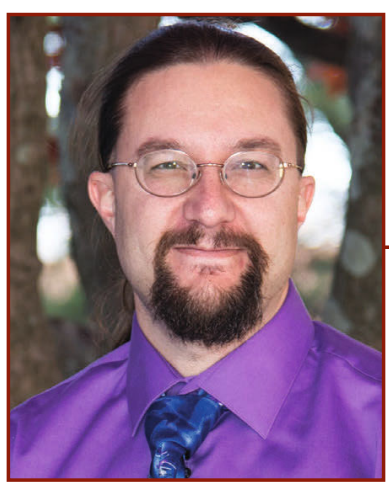

Adam Creuziger

"An additional insight

that we discuss

is that different

mechanisms-

stress near the fillet

and strain near

the notches, for

example-constrain

the deformation of the

sample at different

places."
As first author on the May 2017 JOM technical paper, "Insights into Cruciform Sample Design," Adam Creuziger and his colleagues share new understanding that they've gained in their work on devising a test method for multiaxial deformation. Creuziger is a materials research engineer at the National Institute of Standards and Technology (NIST) Center for Automotive Lightweighting (NCAL). Central to the effort reported on in the $J O M$ article is the creation and calibration of a cruciform sample that can be used by industry without advanced instrumentation.

A key finding presented in the paper is that for this style of cruciform geometry, the fillet diameter is critical. "This will present significant challenges to fabricating built up samples that are made without thinning the center of the sample," explained Creuziger.

"An additional insight that we discuss is that different mechanisms - stress near the fillet and strain near the notches, for exampleconstrain the deformation of the sample at

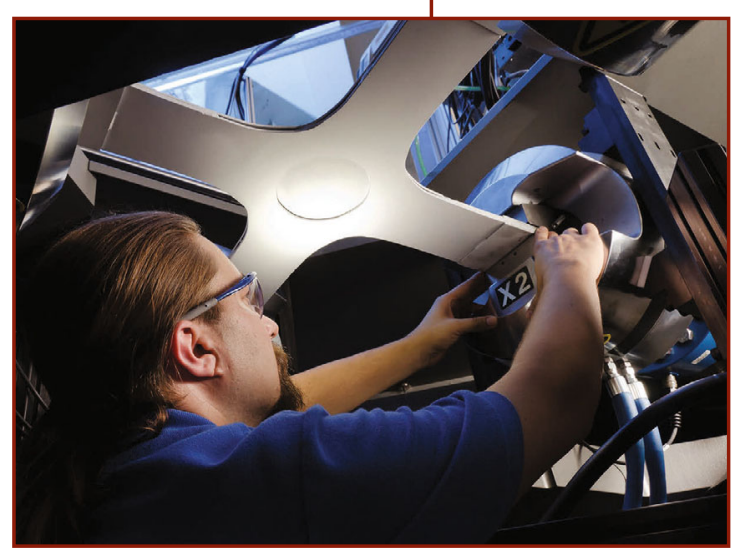

Adam Creuziger installs and aligns a sample inside the NCAL cruciform frame at NIST. different places. These constraints, such as the size and extent of diffuse and localized necks, are currently difficult to model accurately."

Creuziger credits one of his mentors, Tom Shield, at the University of Minnesota-Twin Cities (UMTC), for giving him an early start in his research career as an undergraduate research assistant examining deformation of single crystal copper. Upon graduation from UMTC, Creuziger found another important mentor in Wendy Crone - a former student of Shield's - who served as his Ph.D. advisor at University of Wisconsin-Madison and supervised his work on deformation and fracture of shape memory alloys in her laboratory. "The positive research environment at Madison is something I try to pay forward," said Creuziger.

A post-doctoral research opportunity focused on multiaxial deformation of transformation induced plasticity (TRIP) steels launched Creuziger's relationship with NIST and lead to his current position. Strong mentors have continued to shape his career, both at work and through his engagement with TMS.

"The best phrase that comes to mind is I feel like I've 'found my conference,"” said Creuziger about how TMS has benefited him. "I feel that it's been much easier for me to build a network of colleagues within the framework of repeated attendance at a conference like the TMS annual meeting. You see more familiar faces each year, and it has helped me feel grounded and get over some of the shyness that comes from attending large meetings."

"Do not underestimate the power of networking," Creuziger continued. "I have found that, whether it be job shadowing, formal collaboration, or just informal chats, this is how job opportunities, research collaborations or research 'match making' really happens. Getting out and having those conversations is key." 